\title{
Efectos de la escritura como proceso en la producción de textos argumentativos
}

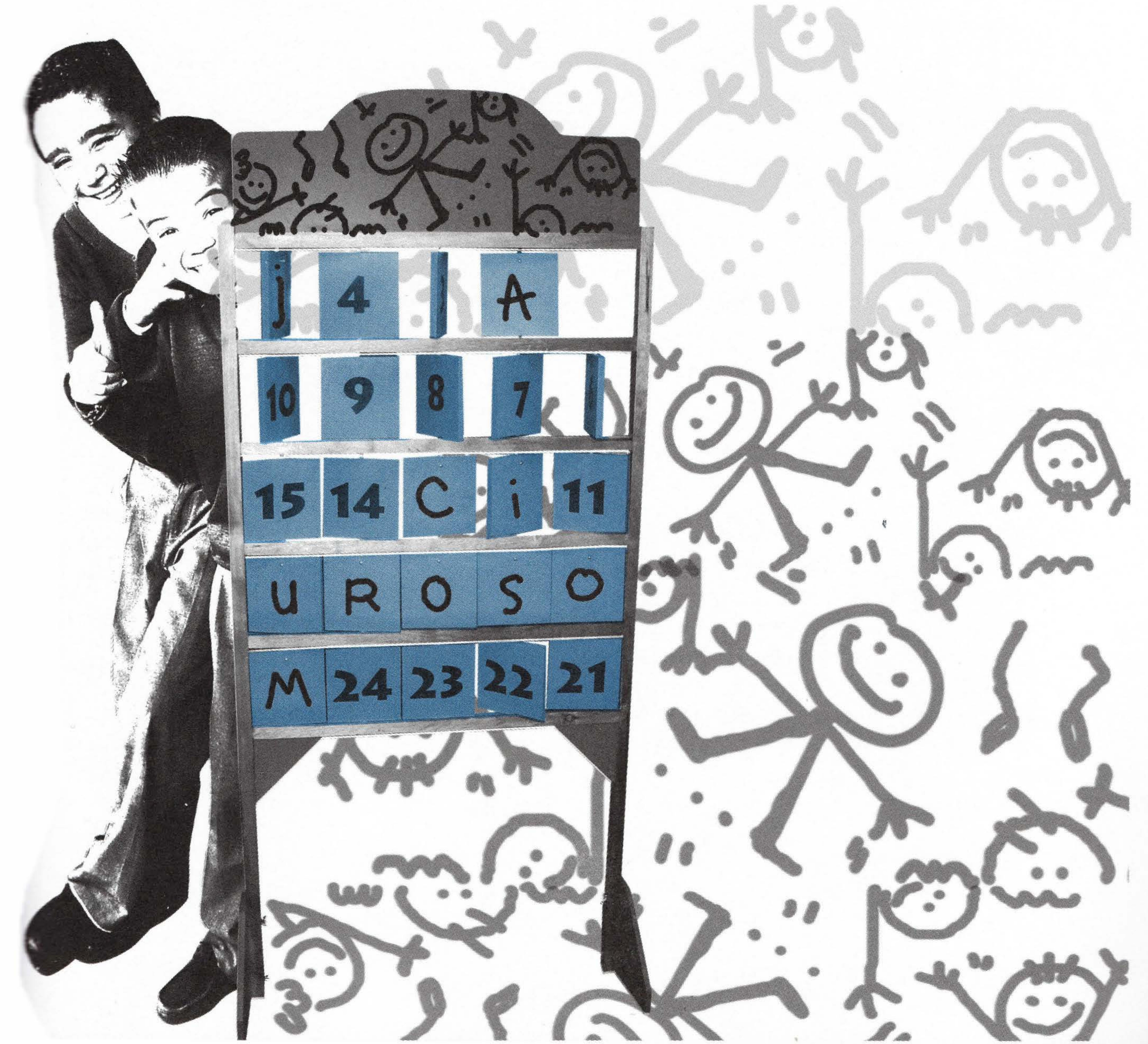


Yudy Ximena Rivera Pulido es Psicóloga de la Universidad Católica de Colombia (2005); Diplomada en lectores competentes (Fundación Alberto Merani). Desarrolló un proyecto en lectura y escritura para docentes no licenciados en la Universidad Nacional de Colombia (2997). Auxiliar de riesgos en el Banco Santander Colombia durante seis años; Psicóloga en el Colegio Departamental de Tocancipá. Actualmente es docente de Básica Primaria del colegio José Joaquín Castro Martínez, Bogotá, D.C. Correo electrónico: yudyximena@gmail.com

\section{Resumen}

Este artículo tiene como propósito describir un Proyecto Disciplinar de Aula -PDAdesarrolladò con estudiantes de $4^{\circ}$ de primaria. El objetivo de este PDA fue el de desarrollar habilidades para producir textos argumentativos a través de la estrategia escritura como proceso. La pregunta que guió este PDA fue: ¿Qué efecto tiene la escritura como proceso en la producción de textos argumentativos de estudiantes de cuarto grado de primaria? El proyecto se desarrolló con estudiantes de una institución educativa distrital de la localidad cuarta de Bogotá. Este artículo reúne evidencia teórica y empírica del efecto positivo que tiene la estrategia utilizada en la producción de textos argumentativos, además de confirmar que la argumentación es una actividad inherente al ser humano y que está presente en él desde la niñez.

\section{Palabras claves: argumentación, escritura como proceso, teorías cognitivas, procesamiento de información.}

\section{Abstract}

This article describes a Classroom Project developed with students of $4^{\text {th }}$ grade of primary school. The aim of this project was to develop skills in order to prepare texts argumentative across the strategy as writing process. The main question was: ¿What effect does the writing process have in the preparation of argumentative texts among these students? The project was developed with students of a school district called Localidad Cuarta in the city of Bogotá, D.C. This article brings together theoretical and empirical evidence of the effect of the strategy used in the production of argumentative texts while it confirms that the argument capacity is an inherent value to the human being and that is present since early childhood.

Key Words: argument, writing as a process, cognitive theory, information processing. 
Fue evidente el crecimiento de la habilidad escritural en los estudiantes de grado $4^{\circ}$ ya que en el desarrollo del periódico las actividades no les fueron impuestas de manera normativa sino que se permitió la participación y decisión del grupo en todo el proyecto. Esto nos permite comprobar que los estudiantes no son sujetos pasivos que están a la espera de la información y dirección que el docente les brinde, sino que ellos construyen y reconstruyen su aprendizaje de acuerdo al vínculo y relación que se establezca entre el docente y el alumno. Es muy importante resaltar el rol del docente como agente desencadenador de desarrollo en el estudiante.

Como parte de la propuesta por el Gobierno Nacional se encuentran los estándares básicos de competencias que son el eje fundamental en las diferentes áreas del conocimiento y los cuales buscan referentes comunes en las instituciones educativas del país. Este proyecto de investigación tuvo en cuenta estándares descritos para el área de lenguaje. Sin embargo, por el carácter transversal de las habilidades comunicativas de este Proyecto de Aula PDA, también se incluyeron aspectos relevantes de otras asignaturas, igualmente encajados dentro de los estándares de competencia del Ministerio de Educación Nacional.

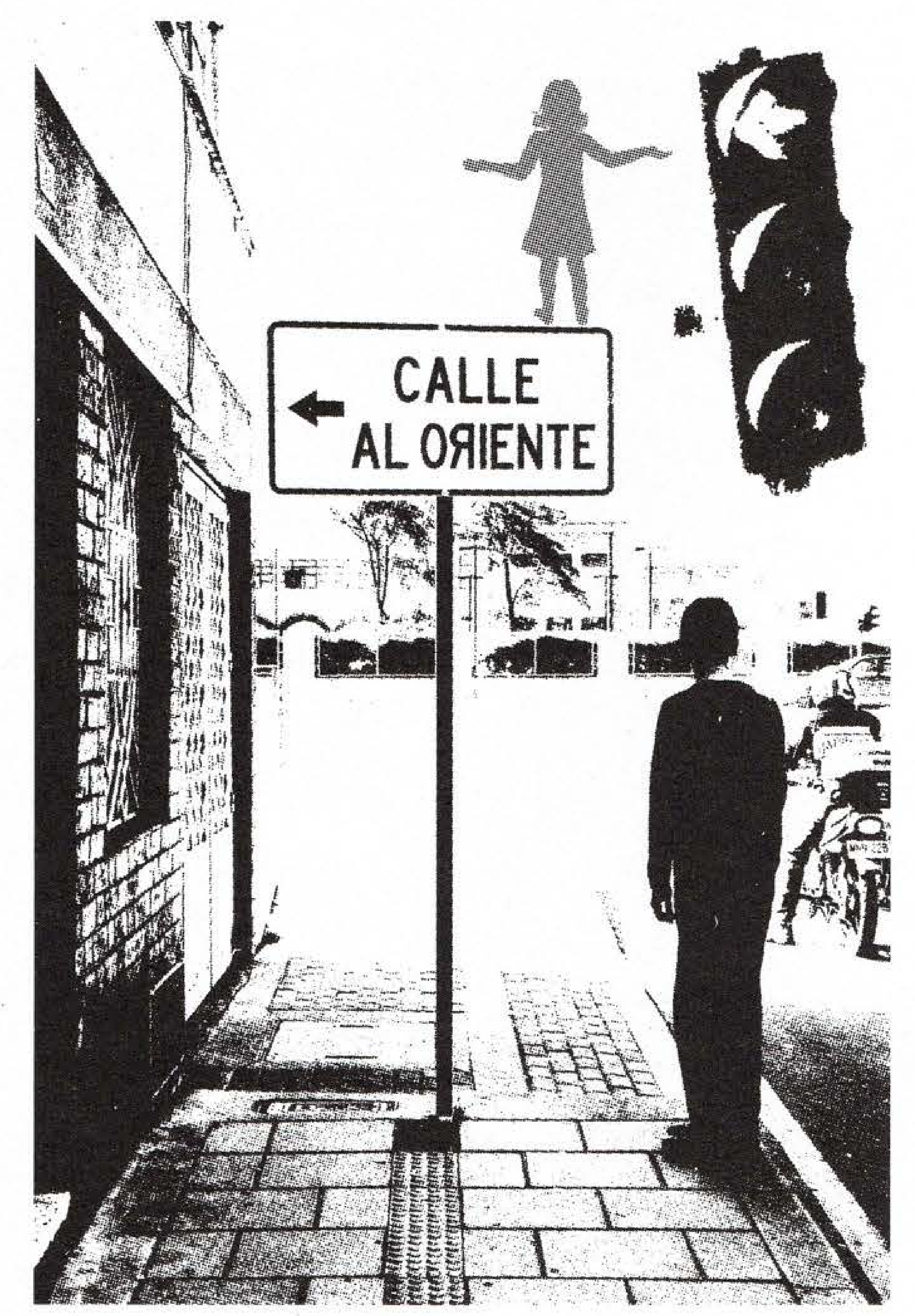

\section{Justificación}

En la observación realizada a los estudiantes de grado cuarto se identificó la existencia de dificultades relacionadas con los procesos de lectura y escritura, entre ellas: baja comprensión de lectura, pobre vocabulario (limitado al contexto), escasa producción textual e inconvenientes al argumentar sus ideas y posiciones personales. Con relación a este último aspecto se puede afirmar que los textos argumentativos de los estudiantes se caracterizaban por estar conformados únicamente por opiniones sobre un tema sin el desarrollo de argumentos; no evidenciaban el uso de conectores lingüísticos; no existía ningún tipo relación entre la posición (conceptual y/o personal) y las justificaciones o argumentos; presentaban dificultades de coherencia; y no se apreciaba una conclusión. A continuación se transcribe, de manera literal, un texto producido por un estudiante del curso, el día 6 de agosto de 2007, que demuestra las dificultades enunciadas anteriormente: 
Yo no estoy de acuerdo con el maltrato infantil porque a unos les puede doler; y no estoy de acuerdo con que los niños vallan a la guerrilla porque de unos a otros se maten y ellos tienen, que respetarsen y cuando ellos llegen a Bogotá pueden matar a niños menores de edad o de pronto a los padres de familia o a la familia completa y a los niños.

En los párrafos siguientes se exponen los referentes conceptuales que guiaron el desarrollo del PDA tales como la definición y estructura de texto argumentativo y la descripción de la escritura como proceso. Adicionalmente, se presentan antecedentes investigativos relacionados con la producción de textos argumentativos en el aula.

En este PDA el texto es entendido como "la unidad lingüística comunicativa fundamental, producto de la actividad verbal humana $[\ldots]$ ". Según esto, posee un carácter comunicativo; pragmático, con sentido dentro de un contexto y estructurado según las reglas propias de la lengua. En particular, el texto argumentativo tiene como base una definición más general de argumentación.
En palabras de Flórez y Cuervo², la argumentación es un procedimiento dialéctico mediante el cual el autor mantiene determinados principios o ideas basado en el razonamiento. Argumentar es, por tanto, ofrecer un conjunto de razones o pruebas en apoyo de una conclusión. Afirman dichas autoras que la argumentación puede tener un carácter objetivo o científico así como un carácter subjetivo o personal. La argumentación objetiva hace referencia a la veracidad y comprobación de la información; a lo impersonal y científico; por ejemplo, artículos científicos o textos académicos. Por su parte, en la argumentación subjetiva el elemento fundamental es el sujeto y la defensa de su propio punto de vista, de sus valores o creencias a partir de razones informales y apreciaciones personales.

El texto argumentativo es concebido como el escrito que pretende definir una tesis y su principal objetivo es el de convencer a los demás de la veracidad y validez de la tesis a través de argumentos objetivos y subjetivos razonables. Según Lo Cascio ${ }^{3}$, un texto es argumentativo sólo si contiene explícitamente formulados una tesis y al menos un dato que la justifique. Se caracteriza por presentar un tema para ser discutido; un protagonista, quien presenta los argumentos (ilocucionario); un antagonista, real o imaginario que debe ser convencido (perlocucionario); un razonamiento para convencer que está sustentado por argumentos, opiniones, datos o hechos; y una conclusión que englobe el tema y los argumentos expuestos. Este autor afirma que la finalidad de un texto argumentativo es influenciar al lector sobre determinado tema para convencerlo, a través de la razón, la persuasión y la afectividad para que asuma una actitud o realice una acción en un determinado contexto.

1 Cassany, D. \& Otros. Enseñar lengua. Barcelona: Ed. Grao, 1994. Pg.44.

2 Flórez, R. y Cuervo, C. El regalo de la escritura - cómo aprender a escribir -. Bogotá, D.C.: Ed. Universidad Nacional de Colombia, 2005.

3 Lo Cascio, V., Gramática de la argumentación. Estrategias y estructuras. Madrid: Alianza Editorial, 1998. 


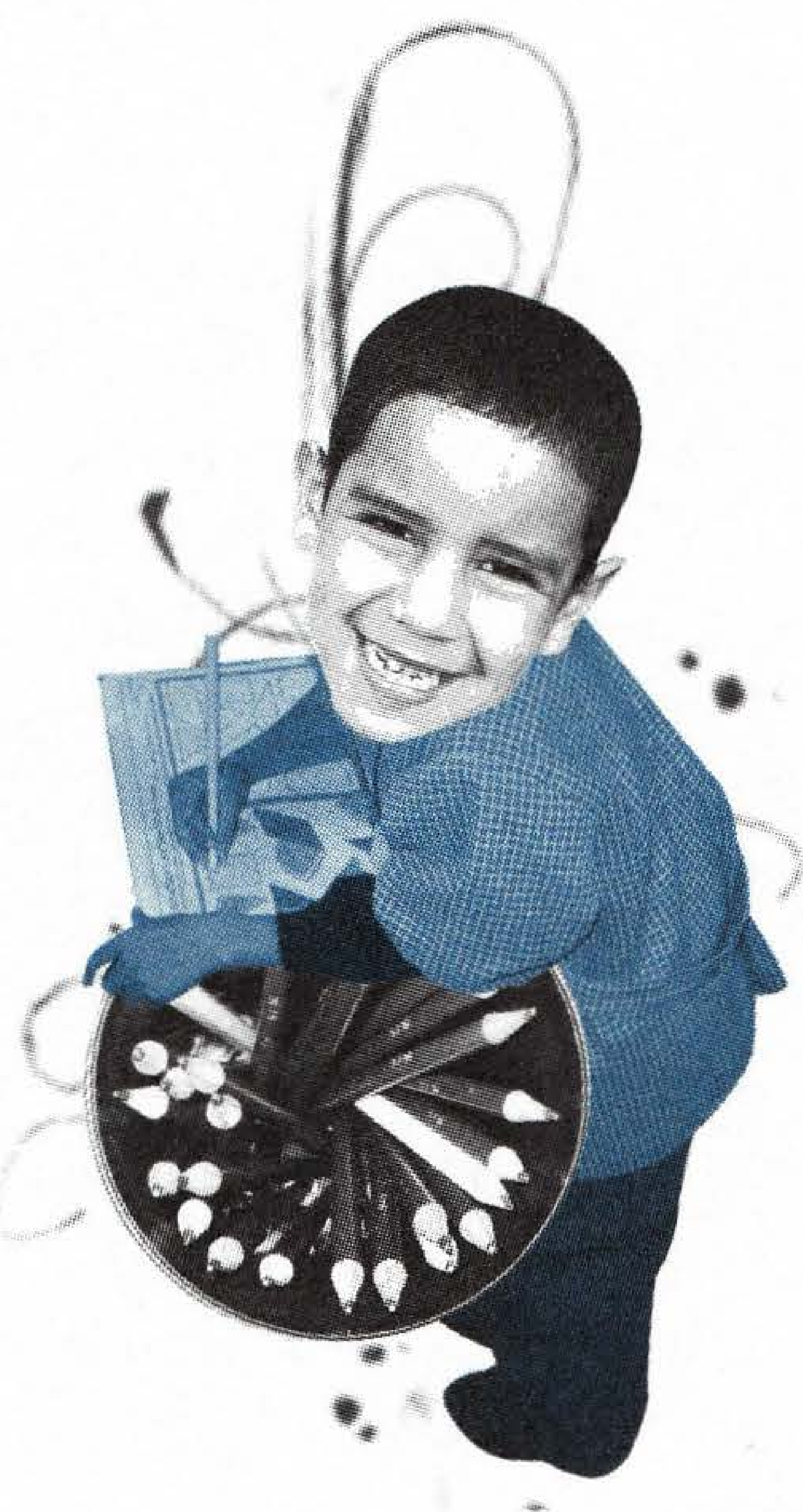

En cuanto a la estructura lógica del texto argumentativo Flórez \& Cuervo ${ }^{4}$ afirman que esta permite interrelacionar varios argumentos para llegar a una conclusión. Las autoras presentan los siguientes elementos que conforman su estructura: a) un objeto o tema sobre el cual se desarrollará la argumentación, generalmente debe estar expuesto al inicio del texto; b) la tesis o posición que asume el autor del escrito respecto al tema; c)los argumentos o razones que son utilizados por el escritor para validar su posición e influenciar al lector; d) la conclusión que presenta una mirada global del cuerpo de argumentación y que generalmente se encuentra al final del texto.

Retomando la estrategia elegida de escritura como proceso, se puede afirmar que alrededor de ella han existido diferentes posiciones teóricas que definen características particulares de la forma como se produce el lenguaje escrito. Si bien, este proyecto se enmarca dentro de las teorías cognitivas y de procesamiento de la información, es importante conocer algunos aportes que hacen las demás concepciones teóricas, por ejemplo, las teorías naturalistas y las teorías socio-constructivistas.

Según los proponentes de las teorías naturalistas, "el desarrollo de la lectura y la escritura se basa en la adquisición del lenguaje" ${ }^{5} \mathrm{Al}$ poseer estructuras cognitivas innatas, el ser humano desarrolla su capacidad de lenguaje de manera natural, producto de la madurez e interacción con el mundo y las oportunidades que posea; esto implica que el desarrollo de la escritura es de forma natural, impulsado por el lenguaje oral y la cultura. Desde esta perspectiva, el lenguaje es funcional, "los niños son capaces de darle sentido al lenguaje cuando satisface las necesidades reales" ${ }^{6}$. Por esto es importante tener en cuenta el contexto donde se desarrollan los niños, ya que, en el caso particular de la escritura, su contenido varía en función del contexto escolar. Florio, Ruane y Lensmire (1989), citados por Irwin y Doyle ${ }^{7}$ sugieren que aprender a escribir no sólo es lograr conocimientos proposicionales y de procedimientos sobre la estructura y las normas del lenguaje, sino que también implica adquirir creencias, valores y actitudes sobre el yo, los otros y el texto.

Las teorías socio-constructivistas hacen énfasis en el conocimiento como artefacto social, producto de un consenso y de la interacción del ser humano con la sociedad. El lenguaje escrito, como parte de las funciones psicológicas superiores tiene una naturaleza social y depende de la comunicación a través de la historia y entre los individuos. Según Lev Vygotsky (1986), citado

Flórez y Cuervo, op. cit.

Irwin, D. \& Doyle, M. (1992). Conexiones entre lectura y escritura. Buenos Aires: Ed. Aique, Pg. 27.

Ibid., Pg. 29.

7 Florio, Ruane y Lensmire, 1989, citados por Irwin, D. y Doyle, M. Conexiones entre lectura y escritura. Buenos Aires: Ed. Aique, 1992. 
por Irwin y Doyle ${ }^{8}$, la lectura y la escritura requieren de autorregulación voluntaria y su adquisición inicia con la interacción de individuos tales como un padre y un hijo o maestro alumno, primero en un plano interpsicológico (entre personas) y luego en un plano intrapsicológico (dentro del individuo).

En los años 1970 un grupo de psicólogos, pedagogos y maestros norteamericanos se interesaron por conocer las habilidades particulares de los buenos escritores, lo cual los condujo a utilizar diversas técnicas de observación y recogida de información, como la grabación en vídeo, los borradores, la verbalización en voz alta del pensamiento, encuestas, entrevistas, entre otras. Esta información fue el soporte de las teorías cognitivas y de procesamiento de información las cuales afirman que la escritura es un proceso que se subdivide en tareas especializadas.

En este paradigma se incluyen autores como Flower y Hayes (1981), citados por Irwin \& Doyle ${ }^{9}$ quienes describen la escritura como un acto consciente dividido en tres fases recursivas: "(1) planeamiento, fase en la que los escritores establecen sus objetivos y hacen planes; (2) traducción, en la que los escritores transfieren ideas en forma escrita, y (3) revisión, en la que los escritores verifican planes y traducciones"10. $\mathrm{Al}$ respecto Cassany (1994) afirma que: "El acto de escribir se compone de tres procesos básicos: hacer planes, redactar y revisar, y de un mecanismo de control, el monitor, que se encarga de regularlos y de decidir en qué momento trabaja cada uno de ellos"11.
La escritura como proceso se apoya en las investigaciones previas de las teorías cognitivas y de procesamiento de información, a la vez que describe de forma detallada cada una de las tareas especializadas o subprocesos que la componen. Para conceptuar la escritura como proceso este proyecto de investigación retomó lo planteado por Cuervo y Flórez (2005) quienes manifiestan que "la escritura ha sido explicada por los modelos cognitivos contemporáneos. Estos dan cuenta de las operaciones mentales que ocurren cuando las personas escriben de manera competente"12. Según estos modelos cognitivos, la escritura es una habilidad compleja que involucra múltiples operaciones de alto nivel (componer, pensar, decidir, crear) y bajo nivel (ortografía, puntuación, caligrafía, corrección de estilo), que a la vez hacen exigencias simultáneas al escritor.

La escritura se desarrolla en varios subprocesos: planeación, transcripción, revisión y edición. La planeación supone una toma de decisiones con respecto al tema sobre el cual se va a escribir, el propósito del texto, la audiencia a quien es dirigido, las fuentes de información a consultar y la longitud y diseño del texto a escribir (Cuervo y Flórez, 2005). Planear el texto significa hacer una proyección y guía del texto a escribir. Este subproceso encuentra soporte en el modelo teórico de Flower y Hayes (1980) (citados por Cassany, 1994), el cual afirma que la planeación, o el hacer planes implica hacer una representación mental, más o menos completa y esquemática de lo que se quiere escribir y de cómo hacerlo e incluye tareas de generación, organización y formulación de objetivos. 


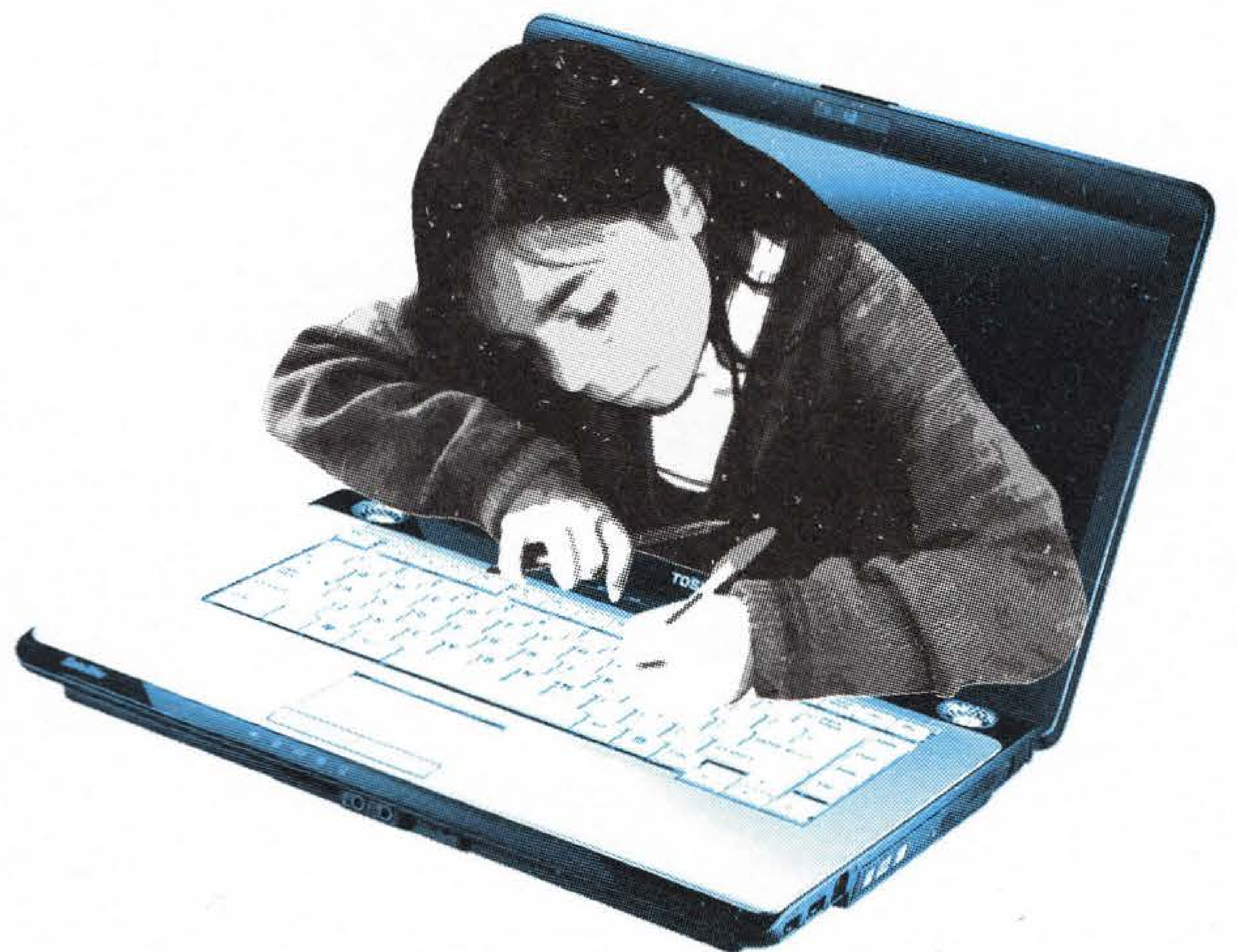

"El subproceso de transcribir o traducir un texto tiene que ver con el acto mismo de escribir sobre el papel o en el computador cuando las palabras fluyen de la punta del lápiz o de la yema de los dedos"13. La transcripción implica escribir un texto organizado lógicamente y que sea inteligible para el lector. El producto de este subproceso es denominado primera versión, de la cual surgieran posteriores versiones según la revisión que se haga de la misma. De la misma forma el modelo de Flower y Hayes (1980) citado por Cassany (1994) plantea como subproceso el redactar cómo la transformación de la planeación en un discurso verbal lineal e inteligible, que respete las reglas del sistema de la lengua, las propiedades del texto y las convenciones socio-culturales establecidas.
La revisión tiene que ver con el mejoramiento de la primera versión y evalúa la lógica o secuencia de ideas en el texto, la precisión de significados, el vocabulario utilizado, el desarrollo del propósito, la congruencia entre el texto y su audiencia, entre otros factores; en el modelo de Flower y Hayes (1994), en la revisión "el autor compara el escrito realizado en aquel momento con los objetivos planificados previamente y lo retoca para adaptarse a ellos y para mejorarlo" 14 lo que implica leer y rehacer el texto para modificar todo lo que sea necesario. La edición se asocia con tareas más automáticas, "relacionadas con las convenciones formales como ortografía, incorrecciones del lenguaje, el uso de mayúsculas, los tiempos verbales, la puntuación o la selección de vocabulario entre otras" ${ }^{\text {"15 }}$.

A continuación se presentan algunos antecedentes investigativos que también guiaron la realización del PDA y dan cuenta del interés por trabajar la argumentación en el aula de clase.

Perelman (1999), escribió un artículo denominado Textos argumentativos: su producción en el aula. En él recopiló algunos conceptos acerca del propósito, estructura, estrategias y dificultádes del texto argumentativo. Así mismo, incluyó la descripción de un proyecto didáctico de textos argumentativos desarrollado con estudiantes de grado $7^{\circ}$ en la clase de informática. El proyecto tenía como eje analizar el impacto de la tecnología en la sociedad y el resultado debía ser una carta de lectores dirigida a un periódico para presentar una postura crítica respecto al uso de la computadora en la producción de textos escritos, un tema que había sido tratado por el diario El Clarín. 
Para desarrollar el proyecto se diseñaron varias etapas: a) cada estudiante realizó una reflexión acerca de cómo se producen textos con la ayuda del procesador; para ello utilizaron una guía de preguntas que orientaban la actividad; b) se presentaron dos artículos de opinión del diario El Clarín los cuales los estudiantes debían leer, resumir por escrito la posición del autor, encontrar las posturas divergentes y hacer un listado de ventajas y desventajas del uso de las computadoras según los artículos; c) los estudiantes diseñaron una encuesta para indagar sobre la relación de los adultos con las computadoras, en particular con el procesador de textos. En esta encuesta se incluyeron los artículos de opinión del periódico y se solicitaba la opinión del encuestado respecto al tema; d)finalmente, los estudiantes elaboraron una carta de lectores dirigida al diario El Clarín para presentar su postura respecto al tema tratado en los artículos de opinión publicados por ese periódico.

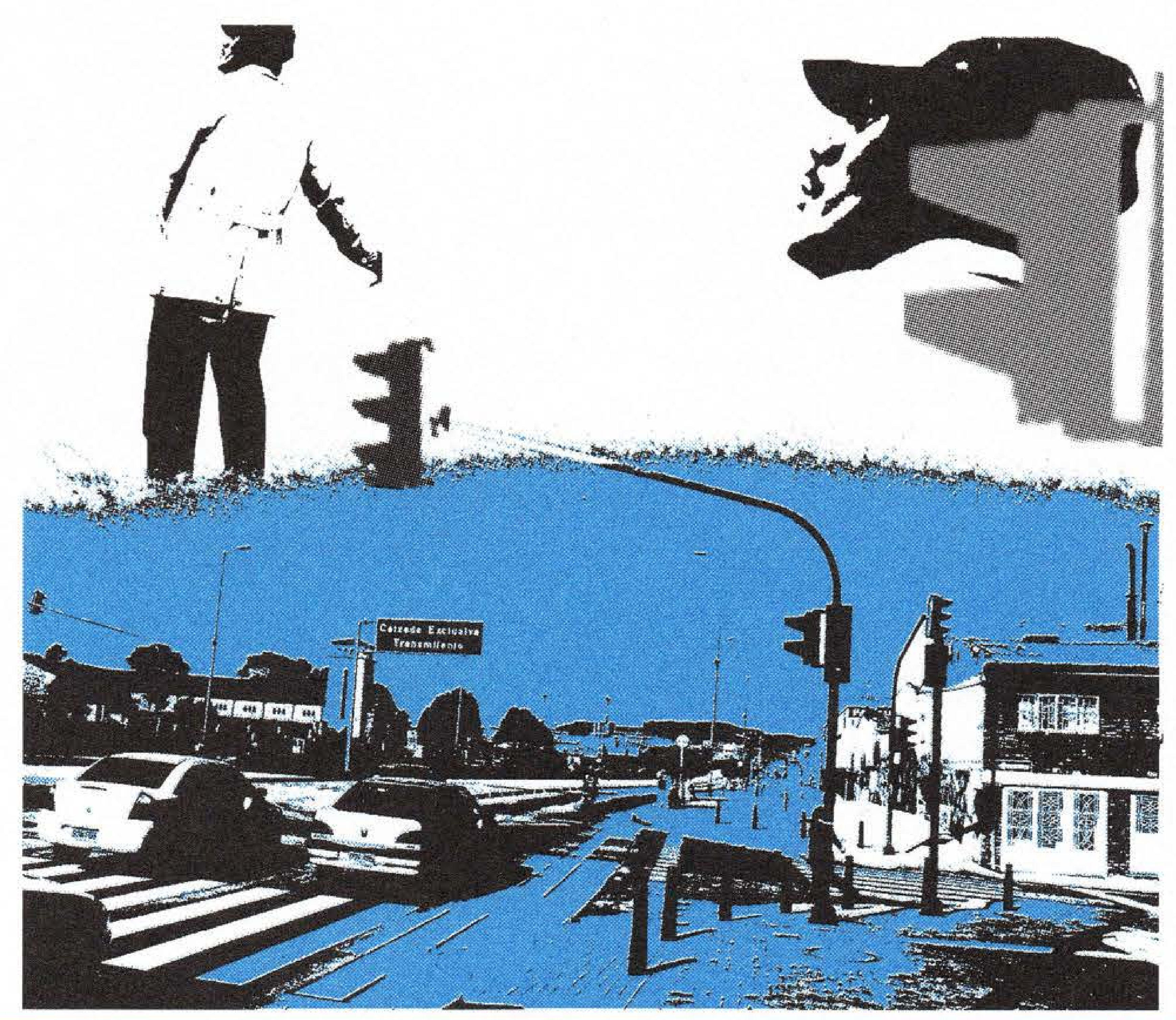

16 Perelman, F. Textos argumentativos: su producción en el aula. Revista En el Aula. №.11. Argentina: Ministerio de Educación de la Nación, 1999, Pg. 23.
El proyecto concluyó que existen diversas formas didácticas de abordar la producción de textos argumentativos y que "las producciones infantiles evidenciaron la enorme complejidad que tienen desde lo discursivo el exponer argumentos ${ }^{\prime 16}$.

La investigación de Perelman (1999) contribuyó a este proyecto de investigación de aula en la medida que brindó información metodológica clara y precisa de cómo producir textos argumentativos en el aula, además de constituirse en evidencia de que los niños sí desarrollan argumentos y definen posiciones personales respecto a temas de opinión que les afectan y que hacen parte de su contexto.

En Colombia, específicamente en Bogotá, Ramírez \& Rodríguez (2005) llevaron a cabo un proyecto de investigación de aula denominado De la crónica periodística colombiana al texto argumentativo corto. En el proyecto participaron estudiantes de $9^{\circ}$ y $11^{\circ}$ grado de una institución educativa distrital. Las docentes preocupadas por el alto nivel de utilización de textos informativos, descriptivos y narrativos que dejaban de lado los textos argumentativos y las dificultades que presentaban los estudiantes para argumentar en cualquier asignatura, decidieron desarrollar esta investigación. 
Según las autoras,

Se ignora, [...], que la capacidad y la necesidad de argumentar están presentes en todos los actos y momentos de la vida. En consecuencia, se pierden oportunidades valiosas para crear un ambiente propicio que oriente a los y las estudiantes en la organización de su pensamiento crítico, a través de la lectura de los argumentos de otros y la manifestación de los suyos, tanto en forma oral como escrita $^{17}$

El objetivo principal de la investigación fue la producción de textos argumentativos cortos a partir de la lectura compartida de una crónica periodística colombiana (El Bogotazo, en Vivir para Contarla de Gabriel García Márquez) en la que se utilizó la escritura como proceso. Los textos serían publicados en el periódico escolar. Conceptualmente definieron la crónica periodística, el texto argumentativo y la escritura como proceso. Por otra parte formularon algunos indicadores de desempeño en tres niveles: pragmáticos, semánticos y morfosintácticos tales como: a) se reconoce una tesis al principio y una sustentación a lo largo del texto; b) el propósito de convencer al lector está presente en el texto; c) el texto presenta diferentes tipos de argumentos para sustentar la tesis; d) los diferentes argumentos se relacionan con los conectores pertinentes; e) el orden sintáctico expresa la intención en forma adecuada.
En el desarrollo metodológico de esta investigación se presentaron tres fases: una línea de base, con una muestra de seis escritos producidos por los estudiantes denominados El Bogotazo; una segunda fase que incluyó la explicación de la teoría de la argumentación, la revisión y corrección del primer escrito, modelación con base en los pasos del proceso de la escritura y talleres de aula, además de la utilización de la observación directa, la aplicación de la encuesta de auto-imagen de escritor, una bitácora de evolución registrada por los alumnos; y una línea final, de seis escritos denominados Cómo alcanzar la paz en Colombia.
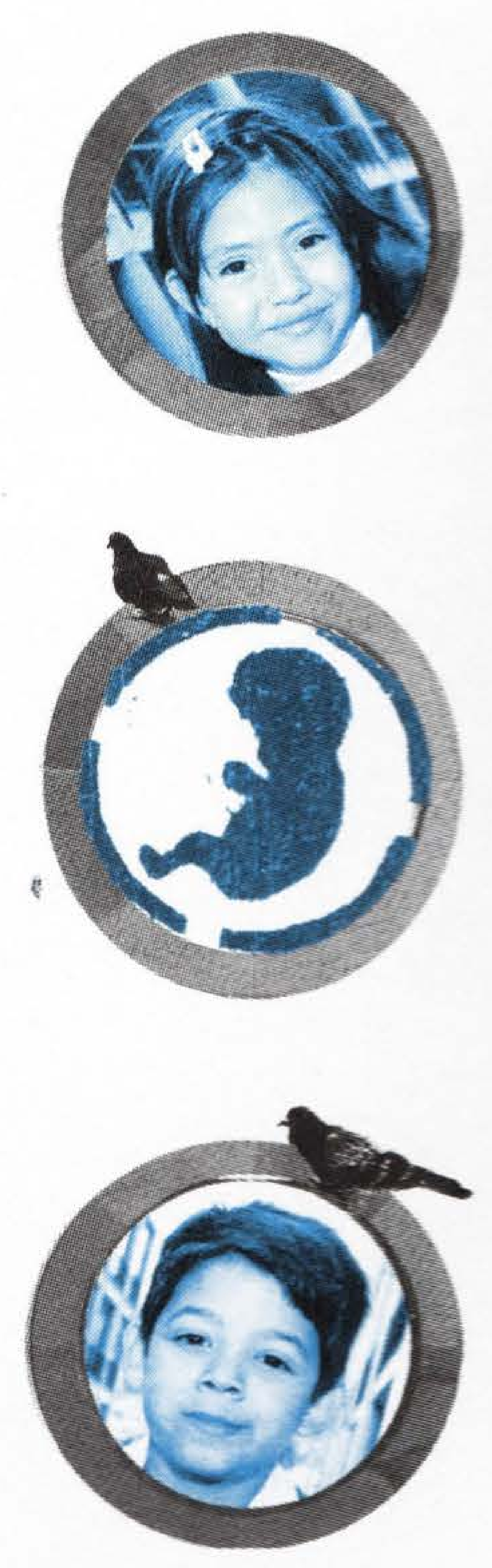

17 Ramírez, B. \& Rodríguez, B. De la crónica periodística colombiana al texto argumentativo corto. En Lenguaje en la educación. Libro Digital, 2005, Pg. 181. 
Como resultado, las investigadoras observaron que los escritos iniciales, pese a que tenían una tesis que argumentar, no evidenciaban verdaderos argumentos o justificaciones que la apoyaran; además de la utilización del parafraseo del autor, sin ningún tipo de posición y sentido de audiencia. En contraste, la versión final de cuatro de los seis escritos evidenció avances significativos en las habilidades argumentativas en el nivel pragmático, "No obstante, es bueno mencionar que fueron evidentes los escollos que los y las estudiantes tuvieron para abandonar el parafraseo, la copia literal, a fin de dar el salto a la presentación de sus ideas producto de sus reflexiones" ${ }^{\prime 18}$. Sin embargo, en los niveles semántico y morfosintáctico se presentaron dificultades en el uso de conectores lingüísticos, los signos de puntuación en la secuencia de las unidades de texto, la ortografía, la utilización de argumentos, el léxico ceñido a la cotidianidad y dificultad en el orden sintáctico. Otro antecedente investigativo lo constituye un proyecto denominado Desarrollo de estrategias argumentativas escritas, en niños de tercero a quinto grado de básica primaria, el cual tuvo por objetivos:

Analizar los modos de argumentación escrita producidos por los niños de tercero a quinto de primaria en tres escuelas distritales de Bogotá $[\ldots]$ y desarrollar, implementar y validar una propuesta pedagógica conducente al mejoramiento de las formas de argumentación escrita de estos mismos niños ${ }^{19}$.
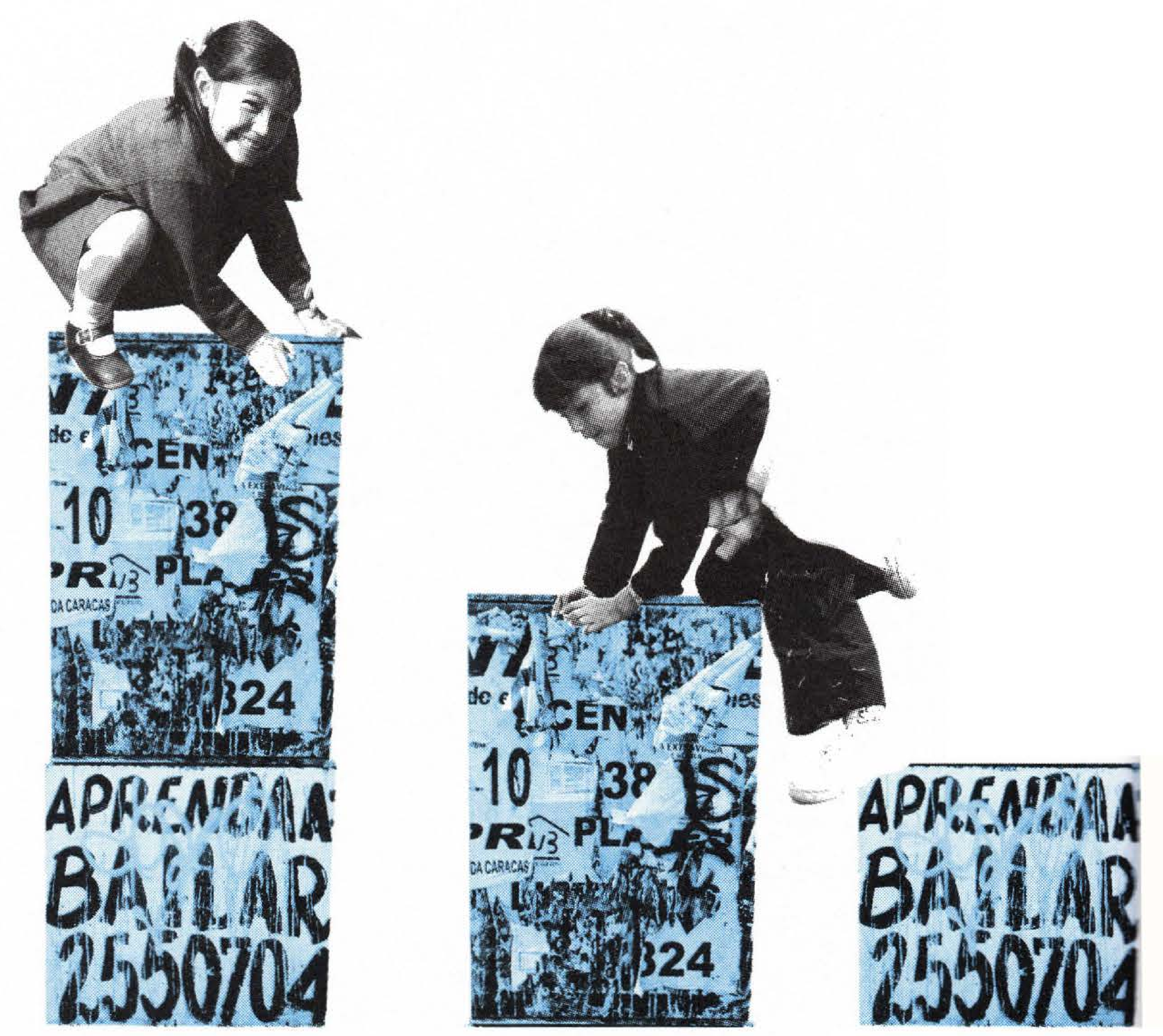

18 Ibíd., Pg. 183.

19 Camacho, V. y Mora, B. Desarrollo de estrategias argumentativas escritas, en niños de tercero a quinto grado de básica primaria. En Educación en lectura y escritura - Investigaciones e innovaciones del IDEP. Bogotá, D.C.: Editorial Magisterio, 2001, Pg. 115. 
En esta investigación, el referente teórico retomó la actividad discursiva de los niños como un acto de habla argumentativa, posición que ha sido desarrollada por autores como Van Dijk, Vignaux, Perelman y Bajtín, "los actos verbales argumentativos tienen por objeto demostrar lo que los hombres creen y desean que sea creído [...] sólo la existencia de una argumentación que no sea apremiante, ni arbitraria, le da sentido a la libertad humana"20. Así mismo, definió teóricamente los principales aspectos de la argumentación: el tema, el propósito, los medios utilizados y los participantes (audiencia).

En el proyecto participaron 300 alumnos y quince profesores de tres escuelas distritales y se desarrolló en tres fases. En la primera se desencadenó texto argumentativo a partir del dilema moral propuesto por Kolhbert (Caso de Heinz). Los estudiantes debían identificar argumentos, determinar su función, organizarlos en una secuencia lógica, predeterminar el punto de vista o tesis y sus respectivos argumentos, reescribir el texto y socialización. Además se expusieron los elementos conceptuales alrededor del texto argumentativo. En la segunda fase se desarrollaron actividades orientadas a la producción de un texto argumentativo en forma semiguiada; el estudiante debía reflexionar sobre una temática particular y poner en práctica los conocimientos adquiridos en la primera fase. En esta fase se utilizó material didáctico que motivara al estudiante a ejercitar su capacidad argumentativa, se elaboraron carteles, se escribieron varios argumentos sobre el tema elegido y se procedió a escribir el texto argumentativo haciendo uso de la escritura como proceso. En la tercera fase se propuso la escritura de una carta dirigida al dueño de una librería, en la cual se solicitaba la donación de algunos libros para la biblioteca de la escuela, escrito que se constituyó como prueba final de la investigación.
Finalmente, Camacho \& Mora (2001) concluyeron que el uso de técnicas o estrategias argumentativas incrementa a medida que el niño crece, y no están determinadas exclusivamente por su interlocutor sino también por representaciones socioculturales, por los sistemas de valor y opiniones asumidas para ser compartidas por el hablante o el escucha, o por un grupo de referencia.

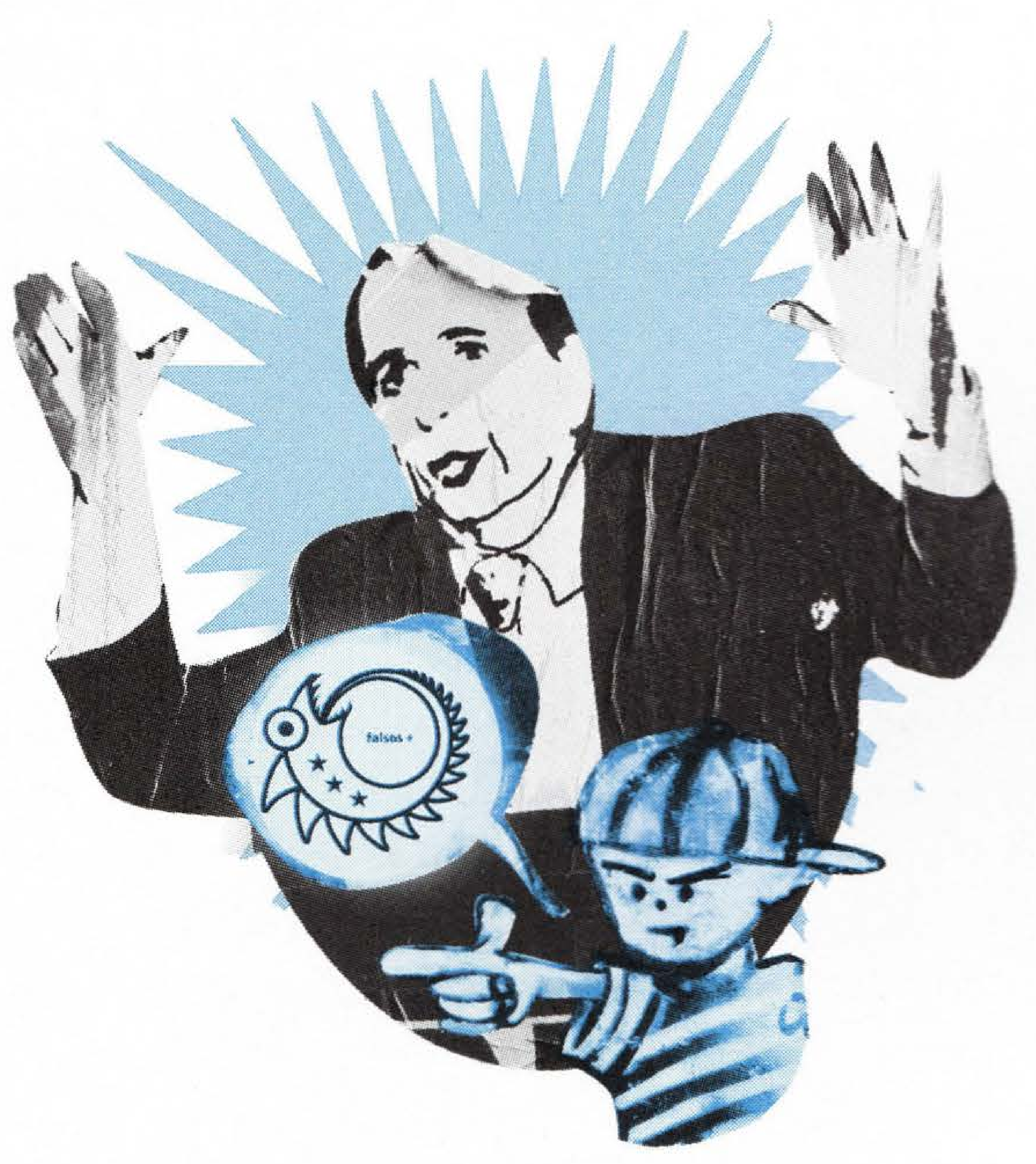




\section{Metodología}

Este proyecto de investigación se llevó a cabo con una población de 30 estudiantes de grado $4^{\circ}$. Sin embargo, para efectos de análisis y procesamiento de datos se seleccionaron 10 estudiantes, cinco de ellos con habilidades para escribir y cinco más con dificultades en el proceso. Se realizó un registro inicial, la implementación de la estrategia y el análisis de los resultados. Para el registro inicial se les propuso a los estudiantes una situación problemática relacionada con el maltrato infantil. Se recontaron algunos eventos que involucraban a los niños en momentos de vulneración de sus derechos y se les solicitó enunciar oralmente si estaban de acuerdo o no con el maltrato infantil y cuál era su opinión personal respecto al tema. Por último, se les solicitó la escritura de un párrafo sobre el tema presentado. Para el análisis de esta muestra inicial se utilizó un listado de indicadores que permitió identificar las habilidades para escribir textos argumentativos. A cada nivel se le asignó un valor de 1 a 4 para poder dar cuenta de los avances de los estudiantes al final de la estrategia; las convenciones y los valores asignados a cada indicador fueron: D: deficiente (1); A: aceptable (2); S: sobresaliente (3) y N: notable (4).

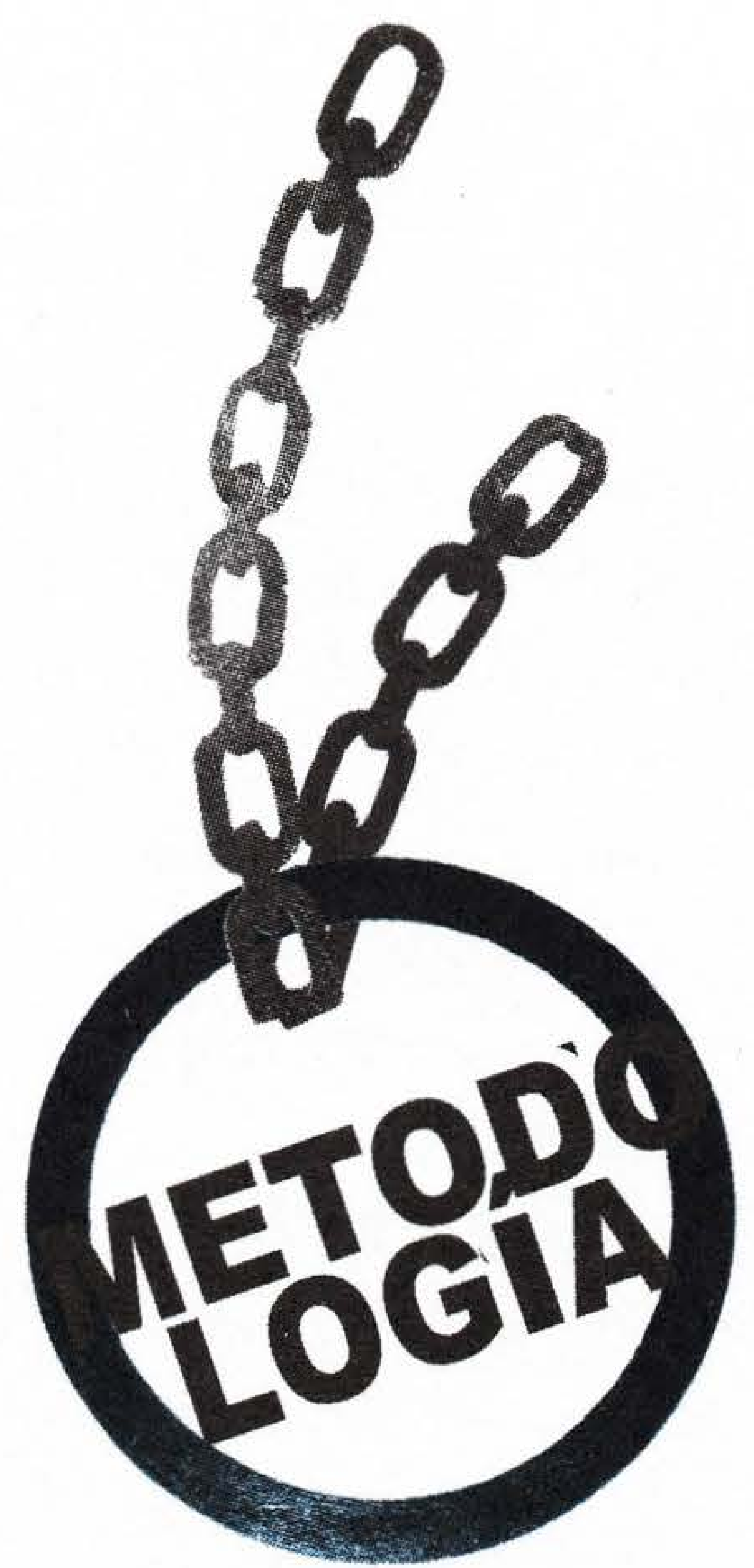

Los indicadores fueron los siguientes:

1. El texto evidencia una proposición o tesis (conceptual o personal) coherente y válida.

2. El texto demuestra argumentos (conceptuales, personales, ejemplos, casos particulares).

3. El texto ofrece una conclusión.

4. En el texto se hace uso de conectores entre segmentos.

5. El texto evidencia la posición del escritor respecto al tema.

En el registro inicial o línea de base los escritos de los estudiantes fueron cortos; nueve de ellos evidenciaron una posición como escritores respecto al tema de manera aceptable; cinco mostraron aceptablemente una proposición o tesis al inicio del escrito; sólo cuatro escritos demostraron argumentos y de manera general fueron ejemplos; tres escritos hicieron uso de conectores entre segmentos y ningún texto evidenció conclusión. Adicionalmente, los escritos del grupo en general pusieron en conocimiento y alerta situaciones familiares y personales que los estudiantes vivencian con respecto al maltrato infantil. 
La ejecución de la estrategia de escritura como proceso se llevó a cabo desde el día 21 de agosto y hasta el 30 de septiembre de 2007. Se desarrollaron siete sesiones de 60 minutos cada una. Se elaboraron registros de observación (subproductos). Finalmente, se analizó el último texto elaborado por los estudiantes para determinar el efecto de la estrategia utilizada. A continuación se presenta en detalle el procedimiento de cada sesión:

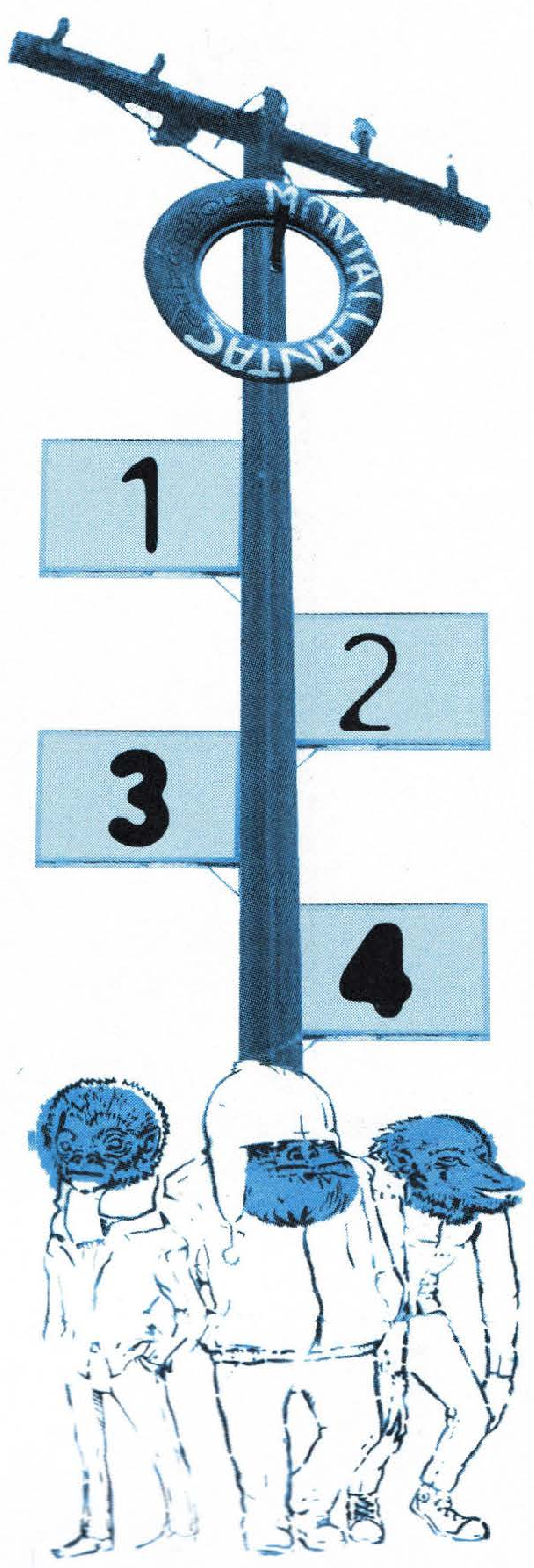

Sesión 1: Planeación

Se presentó a los estudiantes el proyecto de El Periódico que se debía producir en el marco de la asignatura de Lengua Castellana, el cual estaba dirigido a los estudiantes y profesores de básica primaria de la institución. Se realizó la presentación de las secciones del periódico haciendo énfasis en los temas que se debían incluir. Se le solicitó a cada estudiante que propusiera una sección en la cual quisiera escribir un artículo y cuál sería el tema que les gustaría escribir. Luego, se le solicitó a cada estudiante que pensara en un nombre para el periódico y lo escribiera en un papel para después someterlo a votación. Finalmente, se les solicito a los estudiantes traer leído y recortado un artículo del periódico que les hubiese llamado la atención, sin embargo, se hizo un especial énfasis en solicitar a los estudiantes que los artículos fueran relacionados con la niñez.

\section{Sesión 2: Planeación}

El grupo fue dividido en tres subgrupos a los cuales se les asignó una sección diferente y un tipo de texto diferente: Grupo 1: Texto Argumentativo. El tema elegido para este grupo fue Niñez Maltratada y Medio Ambiente. Grupo 2: Texto Descriptivo. El tema elegido para este grupo fue Sucesos en el colegio y en el barrio. Grupo 3: Texto Informativo. El tema elegido para este grupo fue Deportes y Salud. En esta sesión la docente participó como modelo para planear su artículo en la sección de política sobre las elecciones del mes de octubre. Luego, se entregó a cada estudiante varias hojas en blanco y se procedió a resolver, de manera oral y escrita un cuestionario qué contenía los siguientes ítems y que permitió orientar la sesión: tema seleccionado para el artículo, propósito u objetivo del artículo, audiencia del artículo, fuentes de información disponibles, longitud y diseño del documento. 
Posteriormente, se les solicitó a los estudiantes escribir todas las ideas que tuvieran para el artículo (lluvia de ideas), haciendo énfasis en la libertad que tenían para escribir, sin preocupación por normas ortográficas o estilo. Finalmente, se les solicitó a los estudiantes escribir la idea central del artículo a la cual se denominó tesis a desarrollar. Es importante resaltar que se definió tesis como "oración o proposición con sentido completo que se va a desarrollar a lo largo del artículo, es la que guía las otras ideas en el artículo".

\section{Sesión 3: Transcripción}

Esta sesión fue dividida en dos partes: En la primera parte se realizaron las siguientes lecturas: a) Artículo "171 menores de 7 años viven en la calle" publicado en el periódico El Tiempo el día 10 de agosto de 2007 y, b) Situación problema "Porqué la sociedad debe proteger a la niñez" publicado en el libro Nuevo Identidades 4. En la segunda parte se les solicitó a los estudiantes leer lo escrito en la sesión dos y escribir la primera versión de su artículo. En esta sesión nuevamente se resaltó la libertad que tenían para escribir sin preocupación por ortografía o estilo.

\section{Sesión 4: Revisión}

A cada estudiante se le devolvió los escritos producidos en las sesiones 2 y 3 y se les dio las siguientes instrucciones: Cada uno va a leer su artículo en voz alta. Vamos a leer el artículo al compañero de puesto. Nos vamos a responder: ¿entendiste tu artículo? ¿Tu compañero entendió lo que querías decir? ¿Escribiste las ideas que estabas pensando? ¿Se entiende lo que quieres decir? ¿Será que un compañero de un grado inferior entiende nuestro artículo? ¿Repetimos muchas palabras? ¿Qué aspectos debes mejorar? Nuevamente vamos a escribir el artículo retomando toda la información que tenemos y teniendo en cuenta las mejoras y observaciones que resultaron de responder las anteriores preguntas.

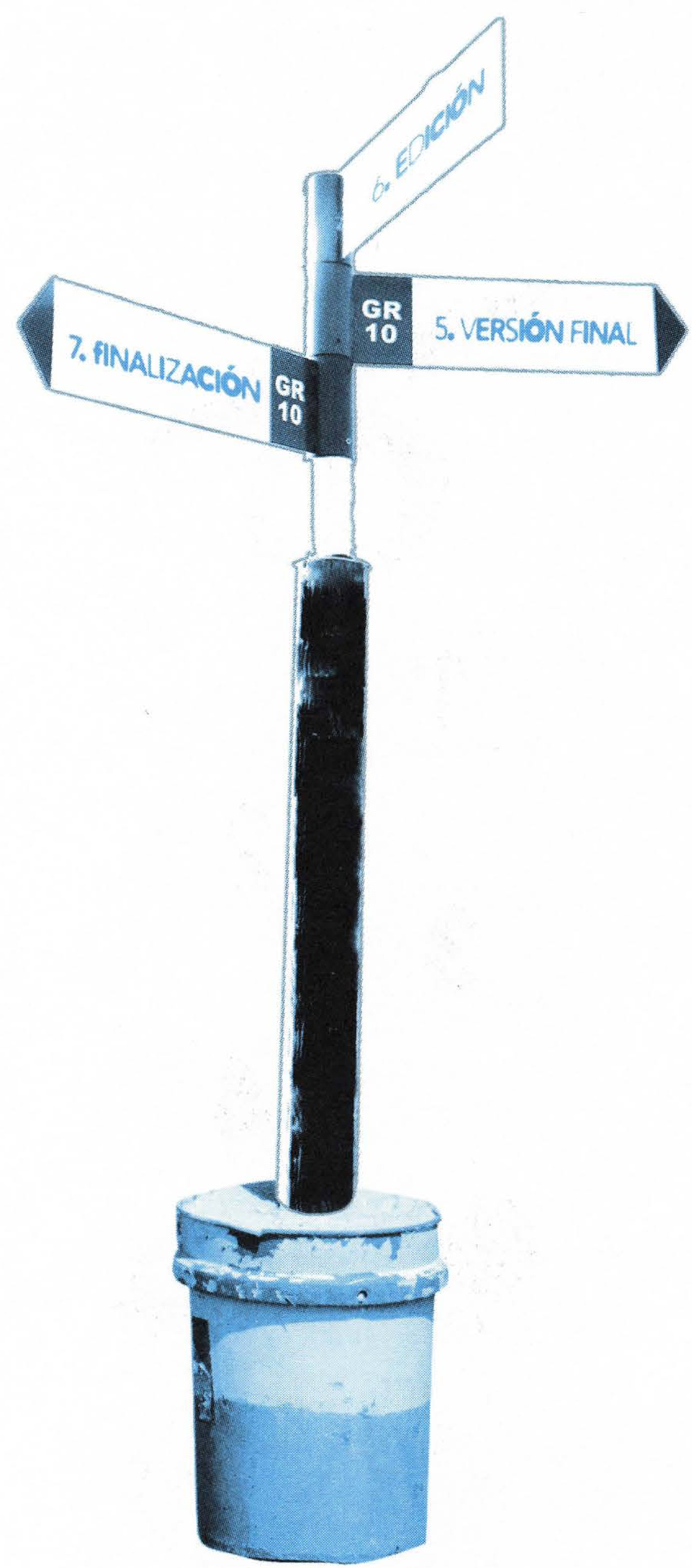




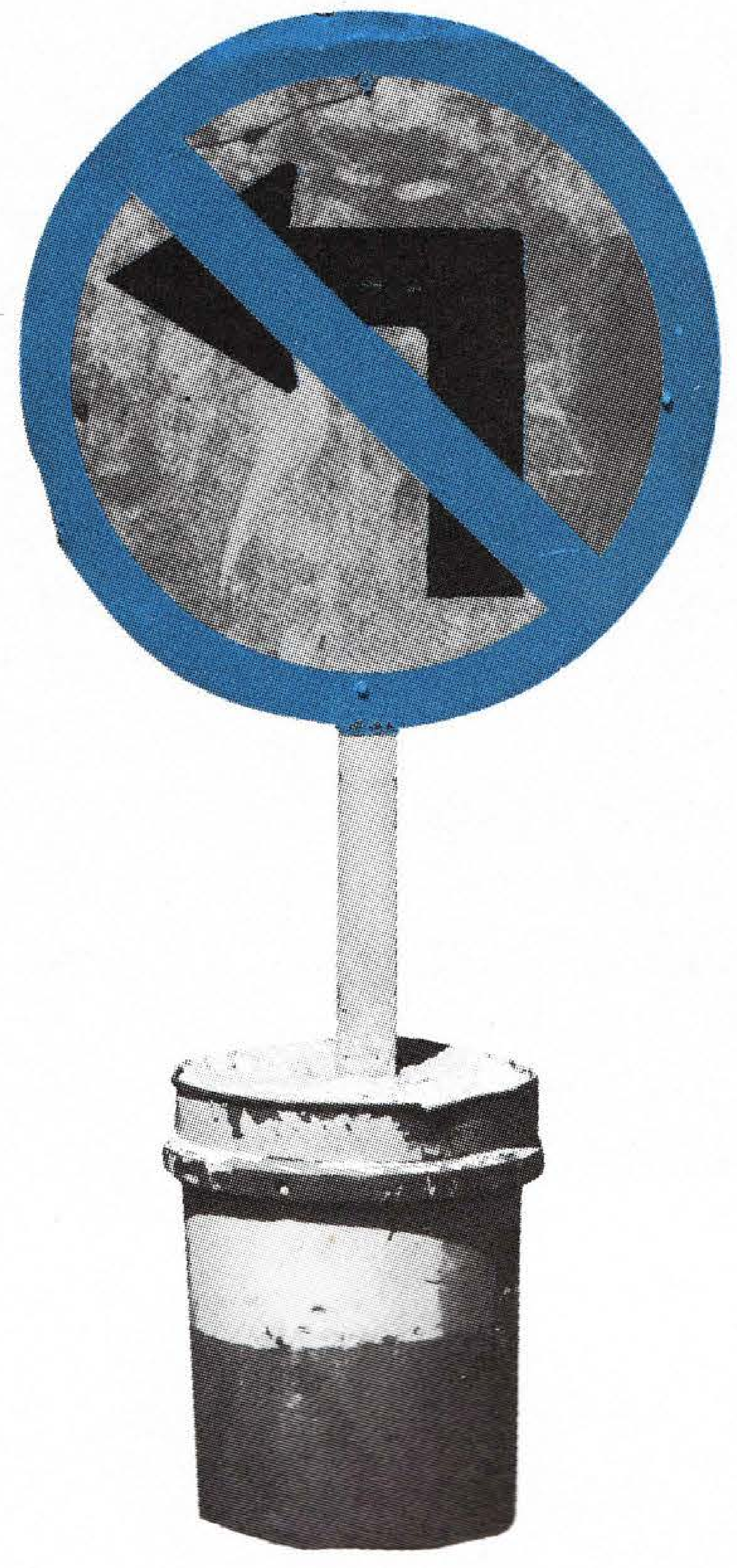

Sesión 5: Versión Final

Se trabajó en el grupo muestra de manera individual. Se realizó el siguiente procedimiento: La docente leyó en voz alta a cada estudiante participante su escrito de revisión. Se le solicitó al estudiante que tomara atenta nota de las oraciones o párrafos que no entendía a medida que se desarrollaba la lectura, estos se iban resaltando y aclarando. De manera conjunta el estudiante y la docente establecieron claridad acerca de las oraciones o párrafos confusos a través de retroalimentación oral. Finalmente, se le solicitó al estudiante que escribiera la versión final del artículo sin olvidar el trabajo y las observaciones que se habían realizado en las sesiones anteriores.

\section{Sesión 6: Edición}

En esta sesión se trabajó en el grupo muestra de manera individual. Se realizó el siguiente procedimiento: La docente leyó en voz alta a cada estudiante participante la última versión del artículo. Se corrigieron los errores de ortografía de manera conjunta: cada palabra que presentara error de ortografía fue señalada por la docente y corregida por el estudiante con ayuda del diccionario. Los signos de puntuación fueron sugeridos por la docente pero fueron los estudiantes los que tomaron la decisión de colocarlos. En cuanto a las ideas que aún no eran claras se releyeron conjuntamente con los estudiantes y se mejoraron de acuerdo a las sugerencias hechas por la docente. Se retomaron oraciones y segmentos del trabajo previo y se agregaron al texto final según la orientación de la docente. Finalmente los textos fueron digitados.

\section{Sesión 7: Edición}

Los textos digitalizados en Publisher tipo boletín fueron revisados por los autores, quienes dieron la aprobación sobre el diseño y la ilustración que le fue insertada. Finalmente se procedió a imprimir los artículos con las revisiones de edición que realizaron los estudiantes. 


\section{Resultados}

En la sesión $\mathrm{N}^{\circ} .1$ el grupo en general se mostró bastante motivado. Participaron en la creación del nombre del periódico "El Mundo del Mañana" y las secciones que se eligieron para escribir fueron: Deportes, Salud, Medio Ambiente, Niñez, Historietas Cómicas y Farándula. Se conformaron los equipos de trabajo entre diseñadores, fotógrafos, periodistas y comité editorial.

Luego, en la sesión $\mathrm{N}^{\circ} .2$ los estudiantes participaron con gran motivación, escribieron sus respuestas con bastante fluidez ya que siempre contaron con la ejemplificación o modelo de la docente, aunque algunas de las preguntas tuvieron que ser explicadas más de una vez para que se llevara a cabo una total comprensión.

La sesión $\mathrm{N}^{\circ} .3$ fue muy provechosa. Las dos lecturas realizadas generaron gran impacto entre los estudiantes. Este impacto se reflejó en los escritos ya que la producción aumentó considerablemente tanto en tamaño como en contenido. A medida que se desarrolló la lectura los estudiantes tuvieron todo el tiempo disponible para hacer comentarios, preguntas, contar noticias que estaban relacionadas con el tema, y escribir de manera libre y espontánea.

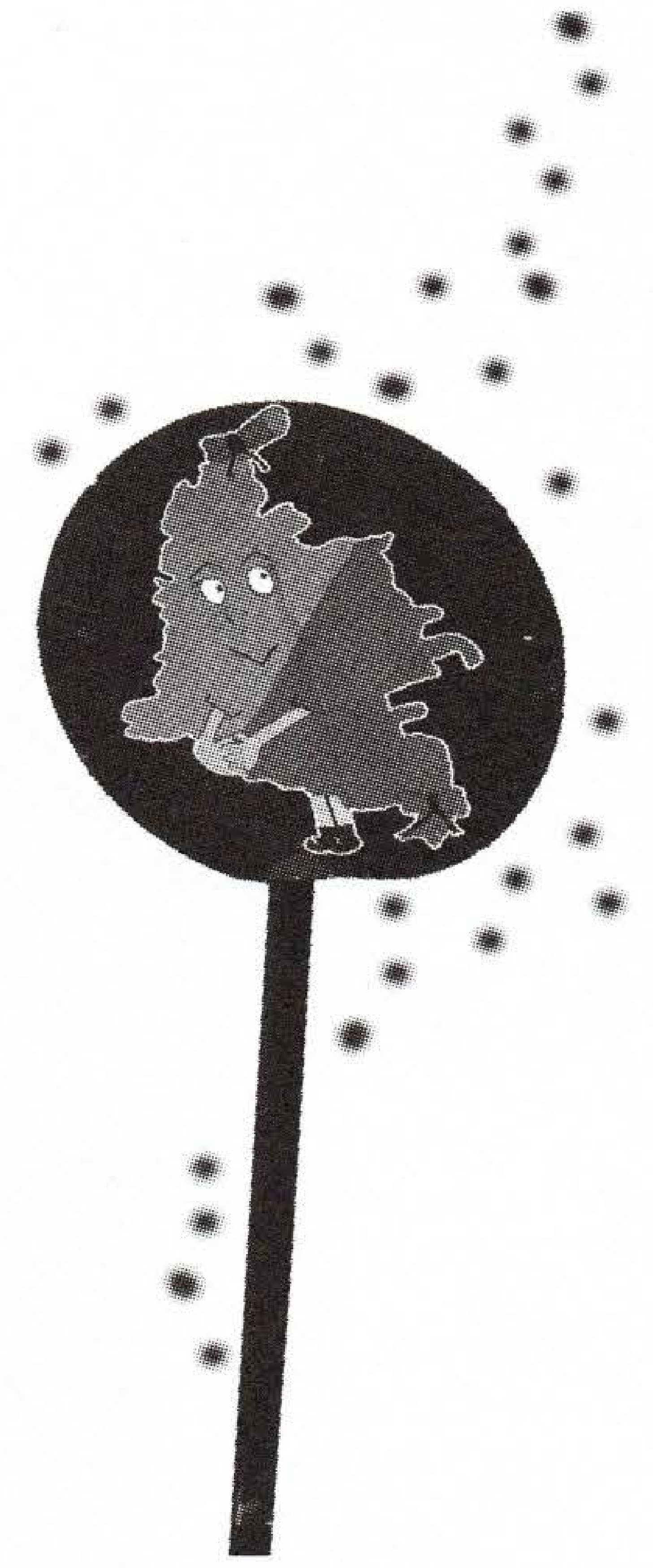

La sesión $\mathrm{N}^{\circ} .4$ se realizó con el grupo en general; sin embargo, el grupo objeto de la muestra recibió mayor acompañamiento en esta tarea. En el desarrollo de la sesión los estudiantes mostraron dificultad para desarrollar la actividad propuesta por lo que se optó por tomar tres ejemplos de texto y corregirlos con la ayuda del grupo en general. Se observó en el grupo que, de manera generalizada, los estudiantes dejaron muchas de las ideas de la primera versión de lado y añadieron unas nuevas, lo cual dificultó el desarrollo de la sesión, al parecer, para los estudiantes es difícil volver sobre su texto y revisarlo.

En la sesión $\mathrm{N}^{\circ} .5$, al igual que en la sesión de revisión, la versión final fue resultado de omisiones de ideas importantes de la primera versión y la revisión y adición de nuevas oraciones. A pesar de haber realizado la actividad de esta sesión de manera individual y de haber orientado explícitamente las oraciones que se podían volver a redactar el resultado fue parcialmente aceptable al esperado en la sesión.

Finalmente, la sesión $\mathrm{N}^{\circ} .6$ fue muy productiva. Adicional al trabajo de ortografía y puntuación que se llevó a cabo, se agregaron a cada texto de versión final segmentos que se habían perdido de la primera versión y la revisión y que hacían que el artículo estuviera más estructurado. Cada estudiante tuvo la oportunidad de volver a revisar el texto de manera minuciosa siempre con acompañamiento y orientación. Adicionalmente, al escuchar a cada estudiante la explicación para las oraciones que eran confusas se evidenció que la argumentación es un acto de habla que está presente en muchas de las actuaciones del ser humano. 
A continuación se presenta una tabla comparativa entre las puntuaciones obtenidas por los estudiantes en el texto inicial tomado como línea de base y posteriormente en la versión final del artículo como línea final. La tabla refleja un aumento en la calificación de todos los ítems en el grupo de muestra. Respecto a la tesis postulada en los escritos, siete de los diez participantes escribieron de manera sobresaliente una tesis válida y coherente, los tres restantes fueron calificados como tesis aceptable. En cuanto a los argumentos, cuatro de ellos escribieron argumentos notables, incluyendo argumentos conceptuales, personales, ejemplos y casos particulares, cuatro más escribieron argumentos sobresalientes y sólo dos obtuvieron una calificación aceptable.
Un solo texto evidenció una conclusión notable, cinco escritos presentaron una conclusión sobresaliente y los demás fueron calificados como conclusión aceptable. En relación al uso de conectores entre segmentos seis escritos lo presentaron sobresalientemente y cuatro lo hicieron de manera aceptable. Por último, se puede evidenciar que cuatro de los diez estudiantes evidenciaron una posición personal sobresaliente respecto al tema y los seis restantes fueron notables en este ítem.

\section{Cuadro $\mathrm{N}^{\circ} 1$ \\ El mundo del mañana}

Tabla comparativa de los resultados por ítem Alumnos (10)

\begin{tabular}{|c|c|c|c|c|c|c|c|c|c|c|c|c|c|c|c|c|c|c|c|c|}
\hline \multirow{3}{*}{ ITEM } & \multicolumn{20}{|c|}{ Comparativo de puntuaciones por participante en linea de base (LB)y linea final(LF) } \\
\hline & \multicolumn{2}{|c|}{ P1 } & \multicolumn{2}{|c|}{$\mathrm{P} 2$} & \multicolumn{2}{|c|}{ P3 } & \multicolumn{2}{|c|}{ P4 } & \multicolumn{2}{|c|}{ P5 } & \multicolumn{2}{|c|}{ P6 } & \multicolumn{2}{|c|}{ P7 } & \multicolumn{2}{|c|}{ P8 } & \multicolumn{2}{|c|}{ P9 } & \multicolumn{2}{|c|}{ P10 } \\
\hline & $L^{22}$ & $\operatorname{LF}^{23}$ & $\overline{I B}$ & IF & $\overline{L B}$ & $\mathrm{IF}$ & $\overline{L B}$ & IF & $I B$ & IF & $\overline{\mathrm{IB}}$ & $\overline{I F}$ & $I B$ & $\mathrm{IE}$ & $\overline{I B}$ & IF & $\overline{L B}$ & $\overline{L E}$ & $\overline{I B}$ & $\overline{I F}$ \\
\hline $\begin{array}{l}\text { El texto evidencia una proposición } \\
\text { o tesis (conceptual o personal) } \\
\text { coherente y válida. }\end{array}$ & 1 & 3 & 2 & 3 & 1 & 2 & 2 & 3 & 1 & 3 & 1 & 2 & 1 & 3 & 2 & 2 & 1 & 3 & 2 & 3 \\
\hline $\begin{array}{l}\text { El texto demuestra argumentos } \\
\text { (conceptuales, personales, } \\
\text { ejemplos, casos particulares). }\end{array}$ & 2 & 4 & 1 & 3 & 1 & 3 & 2 & 4 & 1 & 4 & 1 & 2 & 1 & 3 & 1 & 2 & 2 & 3 & 1 & 4 \\
\hline El texto ofrece una conclusión. & 1 & 3 & 1 & 4 & 1 & 3 & 1 & 2 & 1 & 3 & 1 & 3 & 1 & 2 & 1 & 2 & 1 & 2 & 1 & 3 \\
\hline $\begin{array}{l}\text { En el texto se hace uso de } \\
\text { conectores entre segmentos. }\end{array}$ & 1 & 3 & 1 & 3 & 1 & 2 & 2 & 3 & 1 & 3 & 1 & 2 & 1 & 3 & 1 & 2 & 1 & 2 & 2 & 3 \\
\hline $\begin{array}{l}\text { El texto evidencia la posición } \\
\text { del escritor respecto al tema. }\end{array}$ & 2 & 4 & 2 & 4 & 2 & 3 & 2 & 4 & 2 & 4 & 2 & 3 & 2 & 4 & 1 & 3 & 2 & 3 & 2 & 4 \\
\hline
\end{tabular}




\section{Conclusiones}

A lo largo del desarrollo de este proyecto de aula fue posible verificar y contrastar los diferentes conceptos que se tomaron como referencia en el marco teórico del mismo. Desde la primera sesión y hasta la última, fue evidente el crecimiento de la habilidad escritural en los estudiantes de grado $4^{\circ}$ ya que en el desarrollo del periódico las actividades no les fueron impuestas de manera normativa sino que se permitió la participación y decisión del grupo en todo el proyecto. Esto nos permite comprobar que los estudiantes no son sujetos pasivos que están a la espera de la información y dirección que el docente les brinde, sino que ellos construyen y reconstruyen su aprendizaje de acuerdo al vínculo y relación que se establezca entre el docente y el alumno. En este sentido, es muy importante resaltar el rol del docente como agente desencadenador de desarrollo en el estudiante. A partir de la ejemplificación, de la argumentación, de la significación y la motivación que un docente realice en una clase se origina el desarrollo de las habilidades y potencialidades de los estudiantes con respecto a su aprendizaje en cualquier área del conocimiento.
Es muy importante resaltar que el tema desarrollado a lo largo del proyecto "Maltrato Infantil" junto con "Derechos de los Niños" fue muy significativo para los estudiantes ya que su condición de población vulnerable hizo de los escritos una constante demanda o queja de la situación en la que viven y/u observan. Reflejo de esto se encontró en el desarrollo de la sesión tres, donde el impacto que generó la lectura de los artículos allí mencionados influyó directamente para que los estudiantes escribieran textos ricos en contenido y longitud y presentaran una posición clara y personal con respecto al tema. Esto pone en manifiesto el vínculo existente entre lectura, escritura y oralidad, tres habilidades al servicio del aprendizaje, que en este sentido va más allá de las áreas de conocimiento, trasciende a la realidad del ser humano y la sociedad o el medio donde se desarrolla.

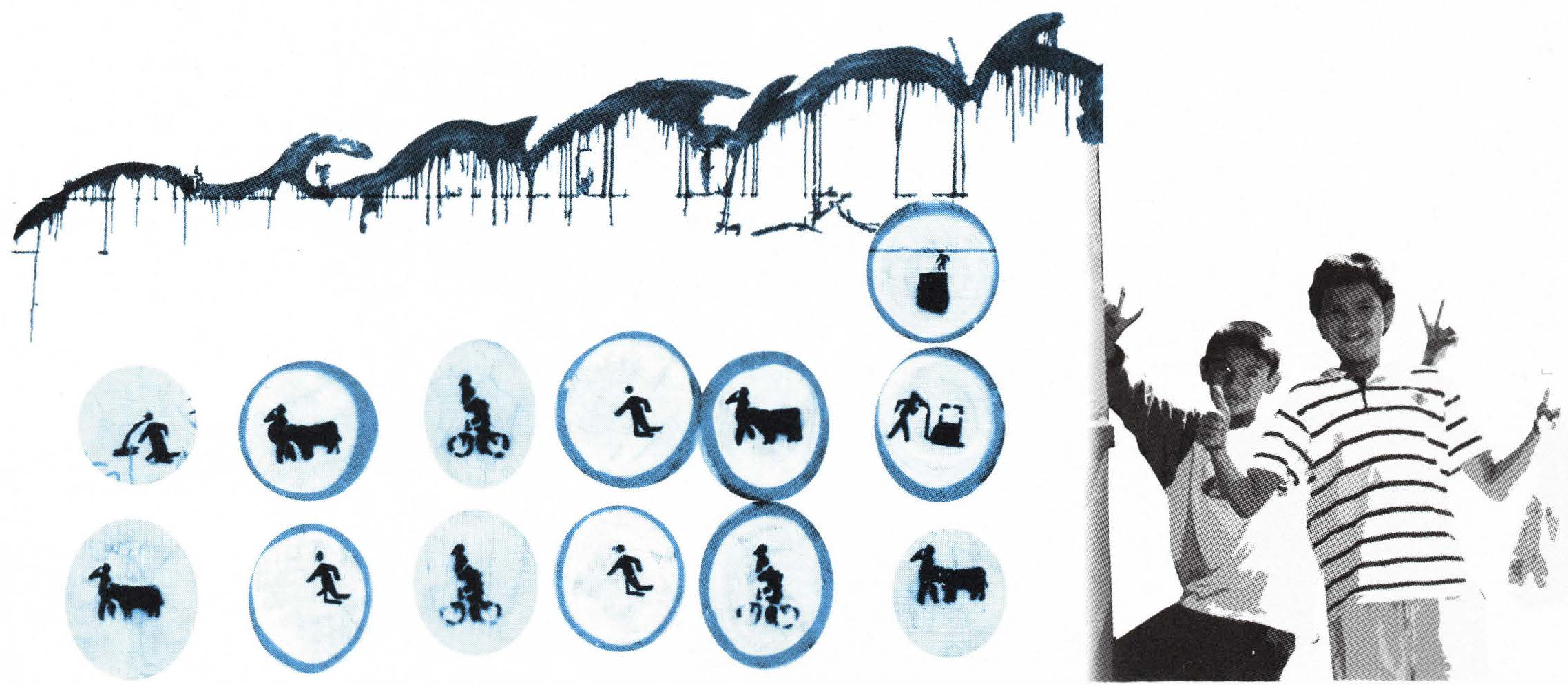




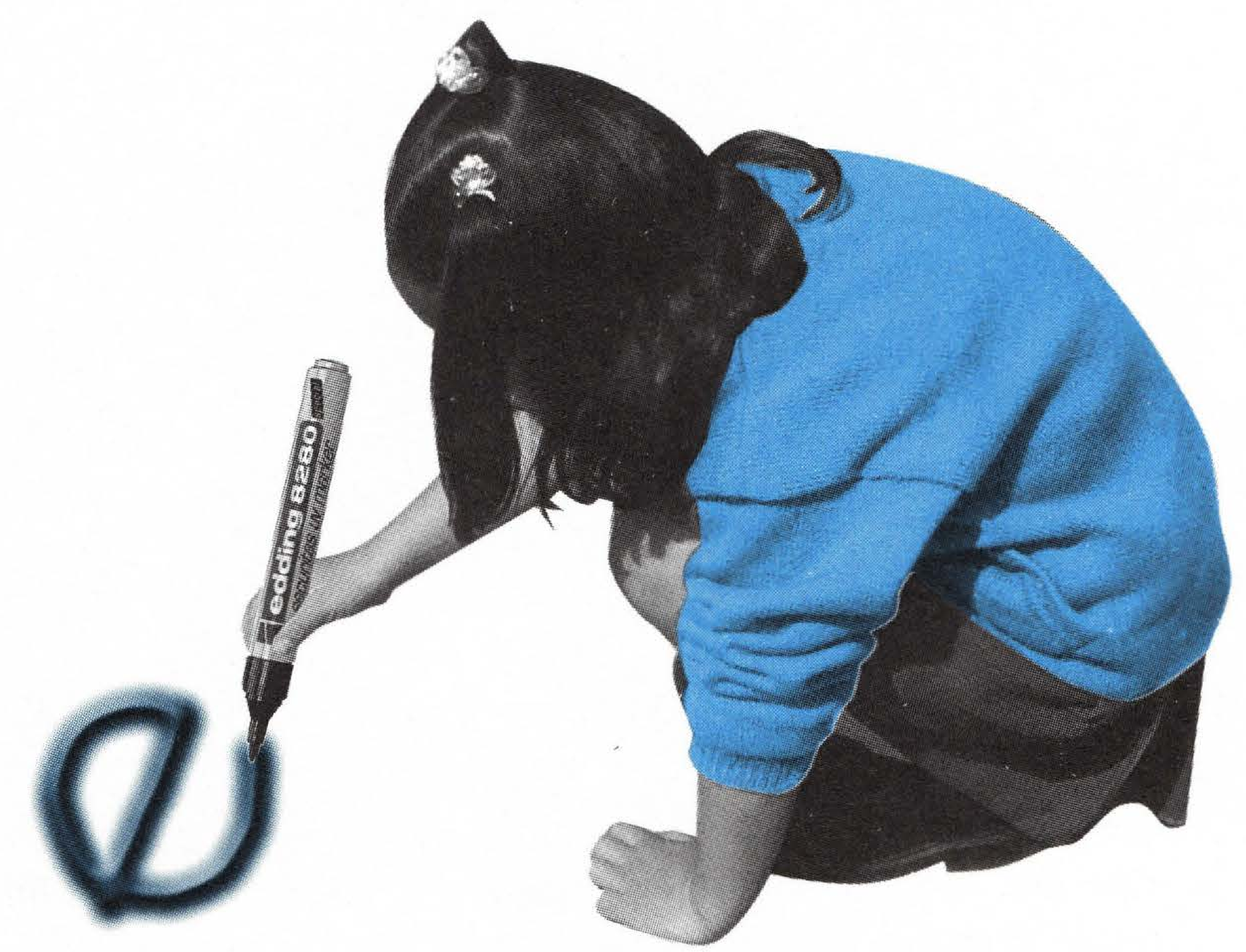

Con respecto a la escritura como proceso se verificó que las habilidades escriturales no se transforman de un momento a otro, como su nombre lo indica, es un proceso constante que involucra todas las actividades cognitivas para su buen ejercicio y que requiere, en un primer momento, de acompañamiento y seguimiento para que se puedan interiorizar sus pautas o subprocesos. Sin embargo, en el transcurso de las siete sesiones desarrolladas en este proyecto se demostró que la estrategia implementada tuvo éxito en todos los participantes y su producción textual. Los textos tomados como muestra evidenciaron un mejoramiento de calidad en su contenido (tesis, argumentos y conclusión) y organización.
Se concluye que la argumentación es un acto de habla que está presente en todo ser humano. La comunicación se mueve alrededor de la argumentación como una estrategia de razonamiento y de compartir subjetividades. La capacidad y la necesidad de argumentar están presentes en todos los actos y momentos de la vida. En consecuencia, se pierden oportunidades valiosas para crear un ambiente propicio que oriente a los y las estudiantes en la organización de su pensamiento crítico, a través de la lectura de los argumentos de otros y la manifestación de los suyos, tanto en forma oral como escrita.

La argumentación es una actividad inherente a la comunicación humana y está latente desde los primeros años de vida, sin embargo, no se le presta la adecuada atención a la forma como se desarrolla en los niños y solo se espera que se haga uso de esta cuando los estudiantes están finalizando la educación secundaria. 


\section{Bibliografia}

Camacho, V. y Mora, B. Desarrollo de estrategias argumentativas escritas, en niños de tercero a quinto grado de básica primaria. En Educación en lectura y escritura - Investigaciones e innovaciones del IDEP. Bogotá, D.C.: Editorial Magisterio, 2001.

Cassany, D. y Otros. Enseñar lengua. Barcelona: Ed. Grao, 1994.

Flórez, R. y Cuervo, C. El regalo de la escritura - cómo aprender a escribir - Bogotá: Editorial Universidad Nacional de Colombia, 2005.

Irwin, D. y Doyle, M. Conexiones entre lectura y escritura. Buenos Aires: Ed. Aique, 1992.
Lo Cascio, V., Gramática de la argumentación. Estrategias y estructuras. Madrid: Alianza Editorial, 1998.

Ministerio de Educación Nacional. Estándares básicos de competencias en Lenguaje, Matemáticas, Ciencias y Ciudadanas. Bogotá, D.C.: Ed. MEN, 2006.

Perelman, F., Textos argumentativos: su producción en el aula. Revista En el Aula. N ${ }^{\circ}$.11. Argentina: Ministerio de Educación de la Nación, 1999.

Ramirez, B. \& Rodríguez, B. De la crónica periodística colombiana al texto argumentativo corto. En Lenguaje en la educación. Libro Digital, 2005. 